\title{
Reflections of Reinvention in Postgraduate Study
}

Peter Halat, Monash University and The University of Warwick

Two years ago, I wrote about how Reinvention itself exposes readers to an interdisciplinary toolbox of research methods (Halat, 2018). Since that time, the journal has continued to produce strong issues under the leadership of Hannah Duffus and Polina Zelmanova, and I myself have made the transition from undergraduate studies into postgraduate research studies.

As I enter the second year of my joint PhD between Monash University and The University of Warwick, I've noted the increasing and persistent pressure that comes with the candidature. For instance, there is a constant need to read and dissect new literature, but to also work on attaining new results. Modern mindfulness studies dictate against trying to complete both tasks at once, but to instead focus solely on one task at a time (Leroy, 2009). Throughout my two-year tenure at Reinvention, I developed an ability to swiftly read and assess undergraduate submissions to the journal, something that has proven to help me in my candidature, as I am confident in transferring the same critical approach to both postgraduate journal articles and my own writing.

I was invited to take part in an alumni panel at this year's edition of the International Conference of Undergraduate Research (ICUR, http://www.icurportal.com/), where I also reflected on the premise of presenting and watching undergraduate research. There are parallels in the benefits of participating in ICUR and Reinvention. To speak more generally about the interdisciplinary toolbox of research methods that Reinvention provides, it is worth noting that, in every issue of the journal, there are numerous examples of successful written research from a variety of disciplines. There are some seemingly intangible criteria that determine the value of a research project, and I contend that one of the best ways to begin to create a recipe for successful research is to immerse oneself in a research environment as soon as possible. Every issue of Reinvention is a prime opportunity for undergraduate students to see valuable research, and start to understand their hallmarks.

As Polina Zelmanova eloquently describes in her previous editorial, many of us are pondering on the past as well as the future in these uncertain times (Zelmanova, 2020). I 
am no different, and as I wonder when I will be able to safely make the trip from

Australia to the UK, I also have to consider how I might need to adapt my project for any scenario. As a theoretician, I am fortunate to be able to conduct productive work from home, which I have been doing for the past six months. In this time, I have been discussing with my supervisors from Monash and Warwick in the exact same fashion: over Zoom. Many people, myself included, were caught off guard by the severity of the pandemic, but also by the meteoric rise of the popularity of online teleconferencing software. Coincidentally, Zoom was the primary teleconferencing software the international Reinvention team used during my tenure, giving me prior experience to standard etiquette of international online teleconferencing, which is not as straightforward as it might seem.

Reflecting on my experience with Reinvention, it was nothing short of an informative and productive journey, which I am confident has helped me in the long term. I thank Reinvention's current Editor, Polina Zelmanova, for inviting me to write this article. It is great to see Reinvention continue its success on a new platform, and to remain as innovative as it always has been. Finally, I would like to wish you, the reader, a safe and healthy future.

\section{References}

Halat, P. (2018), 'Reinvention: An Interdisciplinary Research Toolbox', Reinvention: An International Journal of Undergraduate Research, 11 (2), available at https://warwick.ac.uk/fac/cross_fac/iatl/reinvention/archive/volume11issue2/editorial L, accessed 5 October 2020

Leroy, S. (2009), 'Why is it so hard to do my work? The challenge of attention residue when switching between work tasks', Organization Behaviour and Human Decision Processes, 109, 2, 168-181.

Zelmanova, P. (2020), 'Reinvention: Building a future from our past', Reinvention: An International Journal of Undergraduate Research, 13 (1), available at https://reinventionjournal.org/index.php/reinvention/article/view/631, accessed 5 October 2020. 
To cite this paper please use the following details: Halat, P. (2020), 'Reflections of Reinvention in Postgraduate Study', Reinvention: an International Journal of Undergraduate Research, Volume 13, Issue 2, https://reinventionjournal.org/article/view/723. Date accessed [insert date]. If you cite this article or use it in any teaching or other related activities please let us know by emailing us at Reinventionjournal@warwick.ac.uk. 